\title{
PENERAPAN ROUTER DAN ACCESS POINT SEBAGAI MEDIA PROMOSI WISATA PROVINSI NUSA TENGGARA TIMUR
}

\author{
Yohanes Suban Belutowe \\ Program Studi Teknik Informatika, STIKOM Uyelindo Kupang \\ Jl. Perintis Kemerdekaan 1, Kayu Putih, Oebufu, Kupang \\ Email : yosube@gmail.com
}

\begin{abstract}
East Nusa Tenggara Province is one of the tourist destination areas, one of its prima donnas is Komodo Island which was included in the list of The New 7 Wonders of Nature in 2012. But not only that, there are still many stunning tourist destinations. Kupang City is the main destination before accessing the natural beauty of the East Nusa Tenggara region. In the Kupang City and the Regency of Kupang itself holds many tourist destinations, but the terms of promotion that are still catalog and social media are deemed inadequate. High cost of catalog production and data costs for accessing social media are not cheap either. But by using a router and access point, it is expected that these costs can be eliminated. The router is used to create a hotspot login page. The login page can be modified into a digital catalog (website page) while the Access Point is used to distribute catalog. Hotspots can be accessed free of charge by tourist attractions. Digital catalog can be changed according to the development of tourist attractions. This digital catalog also provides alternative tourism in the Kupang City and other areas in East Nusa Tenggara Province..
\end{abstract}

Key Words: Tourism Digital Catalog, Router, Access Point

\section{PENDAhUluan}

Nusa Nusa Tenggara Timur (NTT) merupakan salah satu Provinsi di Indonesia yang terletak di Kepulauan Nusa Tenggara. Provinsi Nusa Tenggara Timur ini didirikan pada tanggal 14 Desember 1958 berdasarkan Dasar Hukum UU No. 64 Tahun 1958. Tanggal 14 Desember 1958 ditetapkan sebagai Hari Jadi Provinsi Nusa Tenggara Timur. Gubernur pertama Provinsi Nusa Tenggara Timur adalah William Johanes Lalamentik. Provinsi NTT terbentuk dari beberapa pulau besar yang diantaranya adalah Pulau Flores, Pulau Sumba, Pulau Alor, Pulau Lembata, Pulau Rote, Pulau Sabu, Pulau Adonara, Pulau Komodo, Pulau Palue dan Pulau Timor. Selain Pulau-pulau besar tersebut, Provinsi Nusa Tenggara Timur juga memiliki sekitar 550 pulau kecil [1][2]. Letak Provisinsi Nusa Tenggara Timur secara geografis berada di antara $8^{\circ}-12^{\circ}$ Lintang Selatan dan $118^{\circ}-125^{\circ}$ Bujur Timur. Pada bagian timur Provinsi Nusa Tenggara Timur berbatasan dengan Negara Timor Leste dan di sebelah Barat Nusa Tenggara Timur berbatasan dengan Provinsi Nusa Tenggara Barat dipisahkan oleh Selat Sape. Di sebelah Utara Provinsi Nusa Tenggara Timur adalah Laut Flores dan di sebelah Selatannya adalah Samudera Hindia.

Luas Wilayah Provinsi Nusa Tenggara Timur adalah 48.718,10 $\mathrm{Km}^{2}$ dengan jumlah Penduduk sebanyak 5.371.519 $\mathrm{Jiwa}^{[3]}$. Suku Bangsa di Provinsi Nusa Tenggara Timur (NTT) adalah Manggarai, Ngada, Nge Reo, Ende, Sikka, Larantuka, Solor, Alor, Rote, Sabu, Sumba, Lamaholot, Labala dan Kedang. Ibukota Provinsi Nusa Tenggara Timur adalah Kota Kupang ${ }^{[1][2]}$.

Sama seperti Provinsi Nusa Tenggara Barat, Provinsi Nusa Tenggara Timur juga termasuk dalam wilayah Zona Waktu Indonesia Tengah atau disingkat dengan WITA. Zona Waktu Indonesia Tengah ini sama dengan Zona Waktu International GMT +8 atau UTC +8 .

Proviinsi Nusa Tenggara Timur memiliki luas wilayah $48.718,10 \mathrm{Km}^{2}$. Secara administratif, 
provinsi Nusa Tenggara Timur terdiri dari 21 kabupaten dan 1 kota dengan jumlah penduduk 5.371.519 ${ }^{[1]}$ jiwa.

Meskipun Nusa Tenggara Timur (NTT) identik dengan Pulau Komodo yang sudah sangat kesohor hingga mancanegara bahkan masuk dalam daftar The New 7 Wonders of Nature pada tahun 2012 namun potensi wisata di NTT tidak hanya terbatas di Pulau Komodo saja karena masih banyak destinasi wisata terkenal lainnya di NTT yang tak kalah menarik untuk dikunjungi di Kota Kupang dan Kabupaten Kupang sebelum sebelum menyambangi destinasi wisata populer lainnya di NTT misalnya, Pantai Lasiana, Pantai Namosain, Ketapang Satu, Batu Nona, Gua Monyet, Gua Kristal, Pantai Nunsui, Pantai Manikin, Pantai Tabalolong, Bukit Cinta, Air Terjun Oenuse, Air Terjun Tesbatan dan masih banyak lainnya ${ }^{[2]}$. Strategi promosi sampai saat ini melalui media sosial seperti Facebook maupun Instagram. Media katalog pariwisata sendiri yang sudah adadiantaranya majalah Travel GuideTo East Nusa Tenggara(milik Disparekraf NTT), The East Travel Magazine (milik ASITA) serta Katalog Wisata Kota Kupang yang masing-masing katalog wisata tersebut memiliki kelebihan dan kekurangan ${ }^{[4]}$. Pembuatan katalog wisata ini dilihat dari segi produksinya, maka akan memakan biaya cetak yang mahal, namun dengan semakin berkembangnya teknologi dan informasi khususnya pada teknologi jaringan wireless dimana informasi bisa diperoleh tanpa harus mengelurakan biaya tambahan, maka dalam penelitian ini, peneliti memanfaatkan teknologi Router dan Access Point dalam memberikan informasi pariwisata kepada pengunjung pariwisata berbasis mobile tanpa harus mengeluarkan biaya cetak, biaya akses data dan juga katalog versi digital. Katalog digital dapat dijadikan salah satu media promosi pariwisata gratis yang efektif, dimana konsumen dan masyarakat dapat melihat produk unggulan pariwisata dari gadget mereka. Katalog digital dapat dirubah kapanpun sesuai dengan perkembangan pariwisata yang ada.

\section{TINJAUAN PUSTAKA}

\subsection{Pariwisata}

Menurut Undang-Undang Republik Indonesia Nomor 10 Tahun 2009 Pariwisata adalah berbagai macam kegiatan wisata dan didukung berbagai fasilitas serta layanan yang disediakan oleh masyarakat, pengusaha, Pemerintah dan Pemerintah Daerah ${ }^{[5]}$.
Pengertian pariwisata adalah segala sesuatu mulai dari perencanaan perjalanan itu sendiri, perjalanan ke tempat tertentu, tinggal di tempat itu, kembali dan kenangan yang didapat sesudahnya ${ }^{[6]}$. Sedangkan Pariwisata menurut World Tourism Organization/WTO mengartikan sebagai kegiatan manusia yang melakukan perjalanan kedan tinggal di daerah tujuan di luar lingkungan kesehariannya. Perjalanan wisata ini berlangsung tidak lebih dari satu tahun secara berturut-turut untuk tujuan bersenang-senang, bisnis dan lainnya ${ }^{[6]}$. Maksud kata promosi dalam pariwisata adalah untuk memberitahukan, membujuk atau mengingatkan lebih khusus lagi ${ }^{[7]}$. Promosi merupakan suatu proses menyampaikan inforasi kepada target pasar, tentang hal-hal yang menyangkut produk, harga, tempat produk dijual dengan melakukan persuasi agar target mau melakukan pembelian ${ }^{[7]}$. Promosi merupakan salah satu variabel dalam bauran pemasaran yang bukan hanya berfungsi sebagai alat komunikasi antar perusahaan dengan konsumen melainkan juga sebagai ${ }^{[7]}$.

\subsection{Katalog Digital}

Katalog digital adalah sebuah dokumen digital yang dibuat untuk memudahkan calon pelanggan mempelajari sebuah produk atau layanan secara interaktif. Katalog digital juga merupakan media promosi untuk suatu produk yang berbasis multimedia ${ }^{[8]}$

Manfaat dari Katalog Digital yaitu:

a. Kemudahan dalam distribusi dengan adanya teknologi internet, distribusi informasi menjadi lebih mudah dan cepat disampaikan kepada target pasar. dengan menggunakan katalog digital akan mudah dalam mempelajari produk atau layanan yang disediakan. Dalam mempromosikannya bisa menggunakan email atau CD/DVD, yang selanjutnya pelanggan akan mengunjungi halaman catalog digital tersebut tanpa terikat jarak, tempat dan waktu. Selain itu brosur digital lebih mudah untuk digunakan, bahkan tanpa instalasi sekalipun.

b. Infomasi yang lebih akurat dan lengkap dengan memiliki katalog digital, informasi yang akan disampaikan menjadi lebih akurat dan lengkap karena lebih leluasa dalam menampilkan informasi dari produk dan layanan. Berbeda dengan brosur konvensional dimana memiliki keterbatasan dalam penyampaian 
informasi, karena keterbatasan dalam penggunaan media kertas.

c. Informasi menjadi lebih interaktif atau lebih hidup dan informasi yang disampaikan tidak terikat pada teks atau gambar saja, Anda bisa menambahkan fitur suara atau video. Dengan memanfaatkan teknologi 3D, katalog digital bisa mempunyai fitur untuk zoom in, zoom out atau rotate untuk memutarmutar objek secara $360^{\circ}$.

d. Biaya produksi dalam promosi Katalog digital bisa menghemat biaya (budget) produksi dalam promosi, selain itu juga bisa menghemat biaya dalam penggunaan kertas/tinta, jasa cetak, dan jasa distribusi katalog produk dan jasa.

e. Ramah Lingkungan, karena memungkinkan konsumen untuk mencetak katalog hanya pada hal-hal yang dibutuhkan saja, sehingga dapat mengurangi limbah kertas.

\subsection{Router}

Router adalah perangkat keras jaringan komputer yang bisa digunakan untuk menghubungkan beberapa jaringan yang sama atau berbeda. Router merupakan sebuah alat untuk mengirimkan paket data melalui jaringan ataupun internet untuk bisa menuju tujuannya, proses tersebut dinamakan routing ${ }^{[9]}$.

Router berfungsi sebagai penghubung 2 jaringan atau lebih untuk meneruskan data dari satu jaringan ke jaringan lainnya. Router memiliki fungsi utama yaitu untuk membagi atau mendistribusikan IP address, baik secara statis maupun Dynamic Host Configuration Procotol (DHCP) kepada semua komputer yang terhubung ke router tersebut. Dengan adanya IP address unik yang dibagikan router tersebut kepada setiap komputer, memungkinan setiap komputer untuk saling terhubung sehingga dapat melakukan komunikasi, baik itu pada jaringan lokal maupun internet.

Router sangat banyak digunakan dalam jaringan berbasis teknologi protokol TCP/IP, dan router jenis ini disebut juga dengan IP Router ${ }^{[9]}$.

Ruter sangat besar manfaatnya karena router memiliki kemampuan untuk mendeteksi informasi yang akan dikirimkan, apakah data tersebut ditujukan pada host yang berada di satu network ataukah pada host yang berada di network yang berbeda. Router juga mendukung Wireless Distribution System (WDS) dimana setiap router dapat saling terhubung untuk memberikan akses layanan yang lebih luas ${ }^{[10]}$.

\subsection{Access Point}

Access point adalah sebuah perangkat dalam jaringan komputer yang dapat menciptakan jaringan lokal nirkabel atau WLAN (Wireless Local Area Network). Access point akan dihubungkan dengan router atau hub atau switch melalui kabel Ethernet dan memancarkan sinyal wifi di area tertentu. Untuk dapat terhubung dengan jaringan lokal yang telah dikonfigurasikan tersebut, perangkat harus melalui access point ${ }^{[9]}$.

Daya dan frekuensi suatu access point diatur oleh oleh Institute of Electrical and Electronics Engineers (IEEE) pengaturan ini bertujuan agar perangkat access point radiasinya aman untuk manusia. Satndart access point adalah $802.11^{[10]}$

\section{METODE PENELITIAN}

\subsection{Ruang Lingkup Penelitian}

Penelitian ini dilakukan pada Pantai Lasiana Kupang, dengan menggunakan peralatan Mikrotik Router RB951-2n. yang telah memiliki semua kebutuhan router dan gateway untuk personal dan kantor dilengkapi 5 buah port ethernet, 1 buah access point embedded 2,4 GHz, antenna embedded 1,5 dbi. Sudah termasuk power adaptor. Access point TP Link TL-WR720N untuk meneruskan Hotspot yang dibuat pada router sehingga dapat diakses oleh masyarakat.

\subsection{Hotspot Login}

Hotspot login digunakan untuk masuk ke ke halaman login hotspot yang mana halaman login ini telah dimodifikasi menjadi halaman web yang berisi menu untuk mengakses lamanlaman lain yang disimpan pada memori router. Laman-laman tersebut memuat katalog digital untuk mempromosikan pariwisata di Nusa Tenggara Timur. Proses akses dapat dilihat pada gambar 1. 


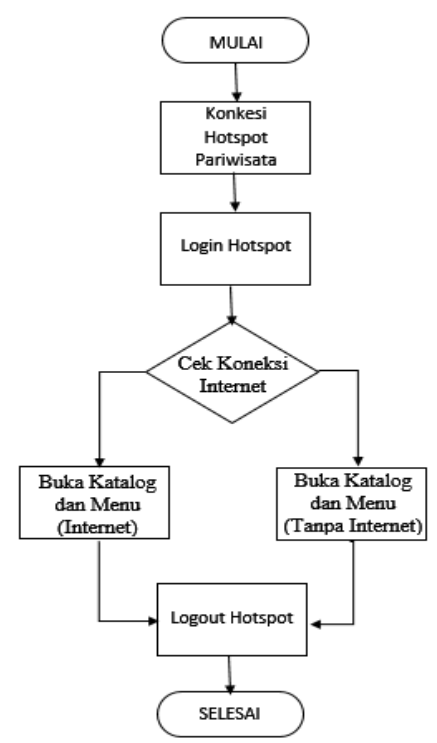

Gambar 1. Bagan Alir Login Hotspot Katalog

Setelah berhasil masuk ke Hotspot, secara otomatis akan diarahkan ke beranda dengan pilihan menu. Pengguna dapat langsung mengakses laman-laman tersebut tanpa harus terkoneksi dengan internet, namun bila ingin mengakses internet, pengguna diharuskan mendaftar pada pos layanan tempat wisata yang tersedia.

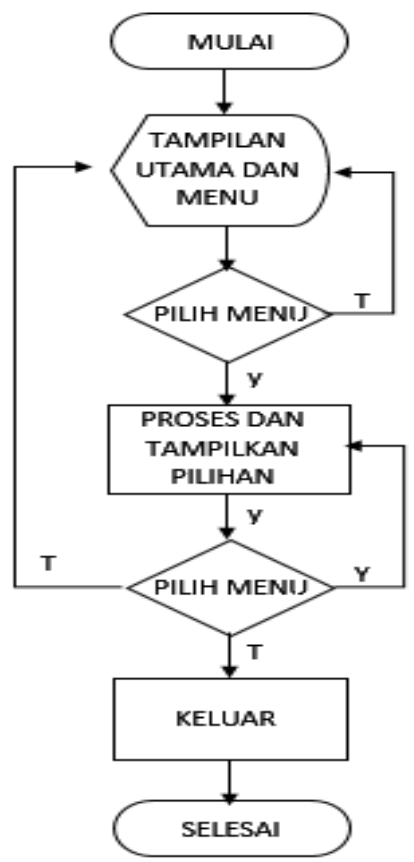

Gambar 2. Bagan Alir Buka Katalog

3.3. Skema Jaringan Hotspot Katalog Pariwisata

Skema jaringan untuk mengakses Katalog digital dapat dilihat pada gambar 3 .

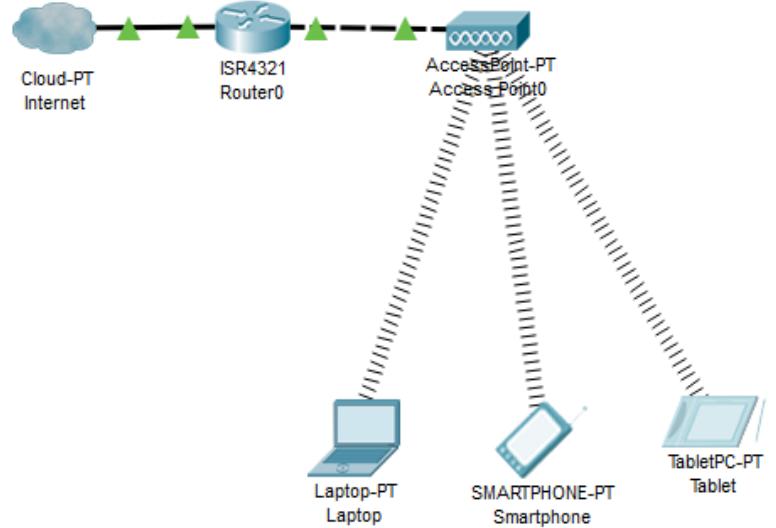

Gambar 3. Skema dengan Access Point

\section{HASIL DAN PEMBAHASAN}

4.1. Desain Katalog Pariwisata untuk Login Page

Katalog digital didesain sedemikian rupa dengan menggunakan software multimedia dan pengalah grafis sehingga bisa menampilkan konten interaktif. Kemudian katalog tersebut diamasukan dalam template mikrotik login page kemudian dimodifikasi sehingga nantinya pengguna dapat mengakses katalog tersebut apabila sudah terkoneksi dengan wireless hotspot mikrotik.

\subsection{Konfiguasi Router.}

Router yang digunakan adalah merek Mikrotik dengan model RB 951Ui-2HnD. Untuk melakukan konfigurasi bisa menggunakan Command Line Interface(CLI) atau dengan menggunakan Graphical User Interface (GUI) Winbox. Pada konfigurasi ini digunakan CLI dan GUI.

\subsubsection{Konfigurasi Ethernet}

Secara default ethernet pada Router Mikrotik belum diberi nama pemberian nama ini untuk mempermudah mengingat ethernet. Ethernet 1 dirubah menjadi Internet, Ethernet 2 dirubah menjadi Local dan Ethernet 3 dirubah menjadi Hotspot.

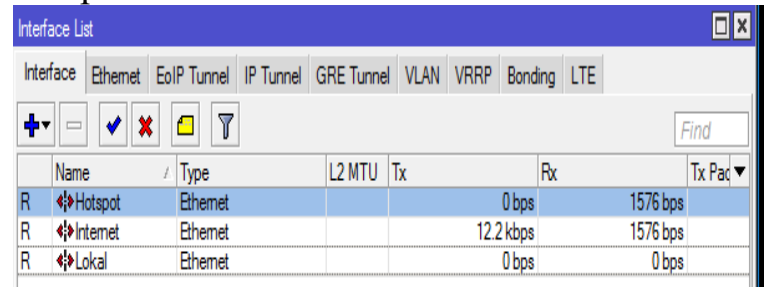

Gambar 4. Pengaturan Thernet

4.2.2. Konfigurasi Ip Adress Internet

Tahap selanjutnya melakukan konfigurasi internet Lewat CLI. Ada 3 langkah yaitu seting 
ip address, seting ip route dan seting dns. Selanjutnya melakukan test koneksi internet dengan melakukan ping ke alamat misalnya google.com.

a. ip address add address $=192.168 .1 .251 / 24$ interface $=$ Internet disabled $=$ no

b. ip route add dst-address $=0.0 .0 .0 / 0$ gateway $=192.168 .1 .1$

c. ip dns set servers=192.168.1.1,8.8.8.8

Konfigurasi dan test koneksi dapat dilihat pada gambar5.

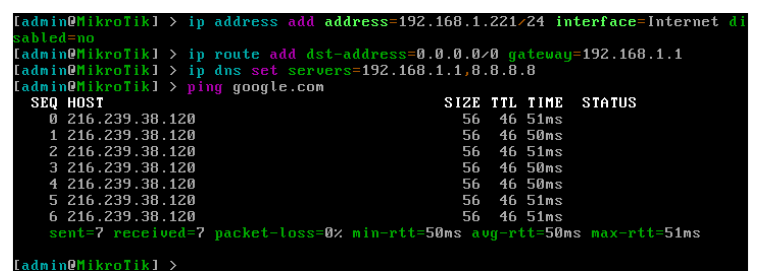

Gambar 5. Seting Internet dan Test Koneksi

\subsubsection{Konfigurasi Ip Address}

Konfigurasi Ip Address lokcal diperlukan bagi administrator untuk login dan melakukan perubahan dan melakukan pembaharuan halaman login (login page) pada router. (gambar. 6). Sedangkan Konfigurasi IP Hotspot diperlukan sehingga pada konffigurasi Hotspot dapat mengenal langsung interface yang digunakan. (gambar 7). Hasil konfigurasi dapat dilihat pada gambar 8 .

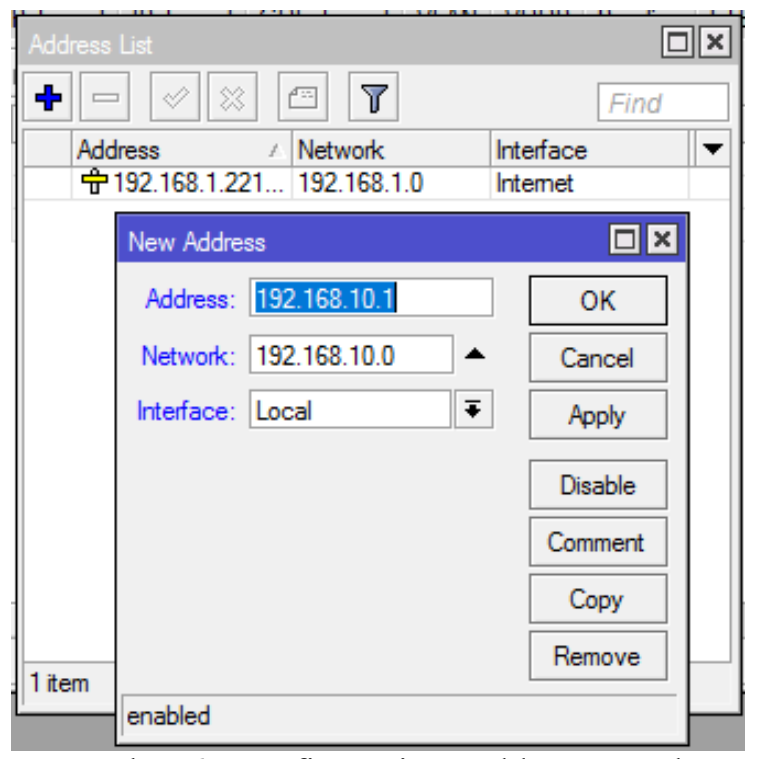

Gambar 6. Konfigurasi IP Address Local

\subsubsection{Konfigurasi IP Adress Hotspot}

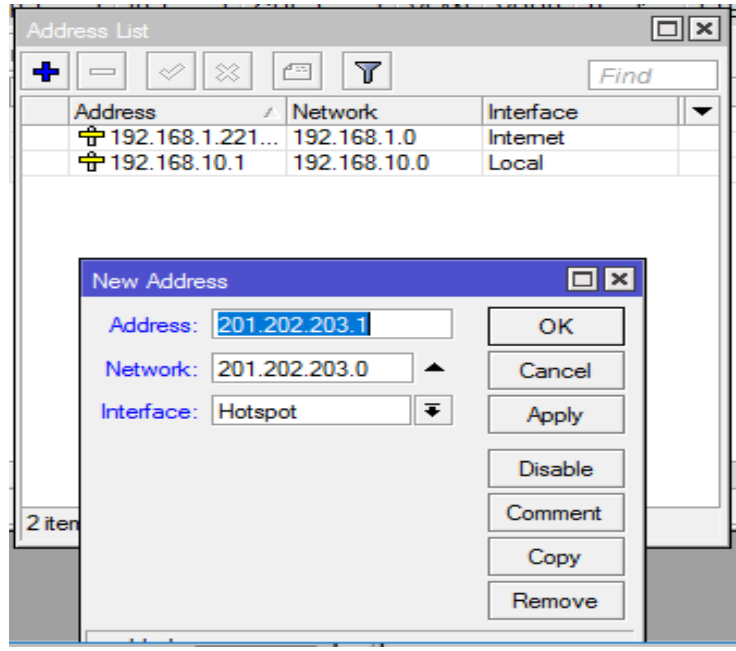

Gambar 7. Konfigurasi IP Hotspot

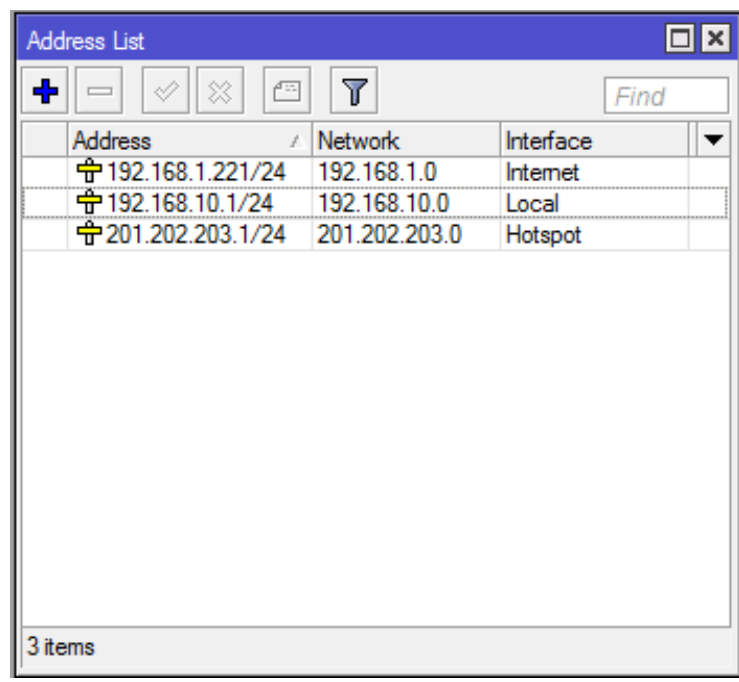

Gambar 7. Hasil Konfigurasi IP Address

\subsubsection{Konfigurasi Hotspot}

Konfigurasi Hotspot digunakan untuk menjalankan hotspot dan memasukan template laman Katalog digital menggantikan laman login page default hasil konfigurasi hotspot.

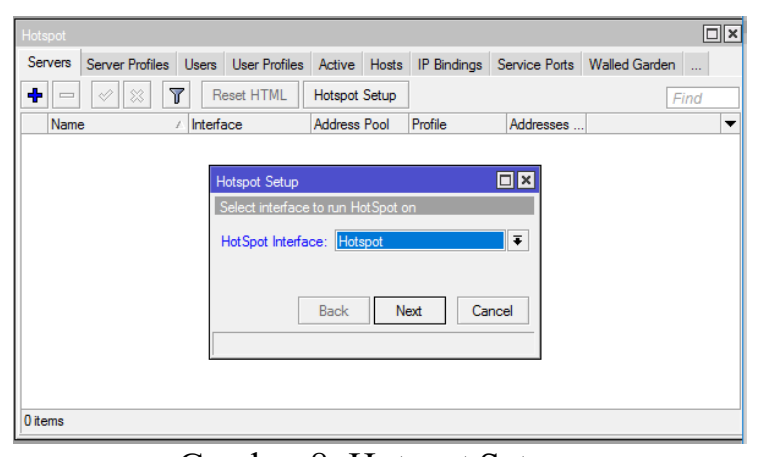

Gambar 8. Hotspot Setup 


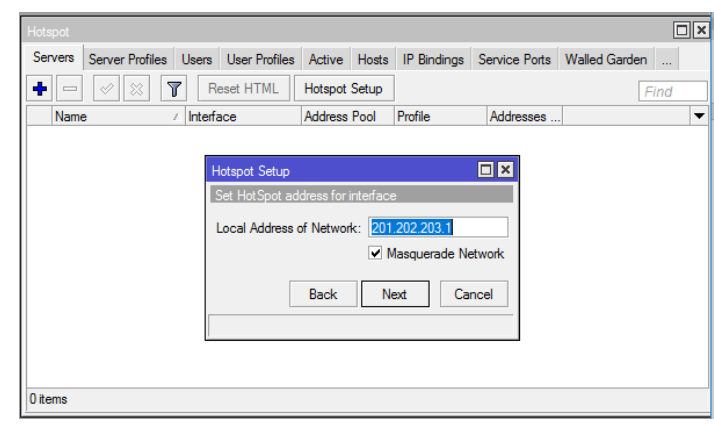

Gabat 9. IP Addres Hotspot

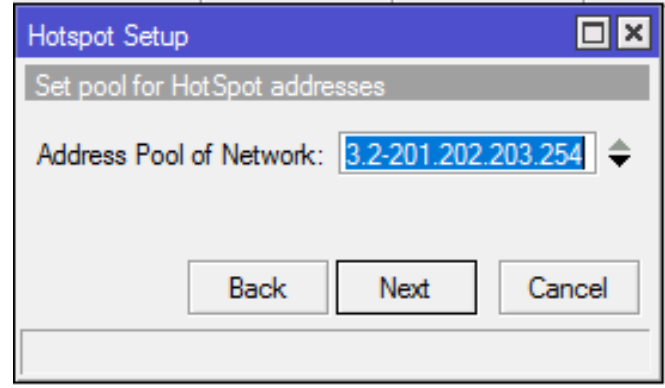

Gambar 10. Address Pool Hotspot

Pada pilihan Sertifikat dan SMTP, dibiarkan saja (kosong), dikarenakan tidak ada service untuk setingan tersebut, Selanjutnya seting DNS Server dan nama DNS.

DNS Server adalah IP Address Hotspot dan Nama DNS katalogntt.com. Selanjutnya masukkan kata sandi (password) yang diinginkan untuk admin.

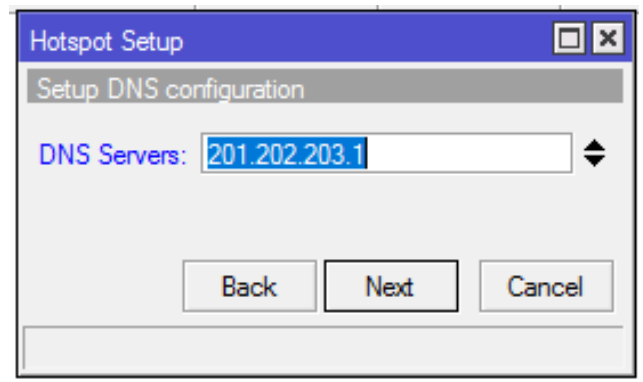

Gambar 11. Seting DNS Server

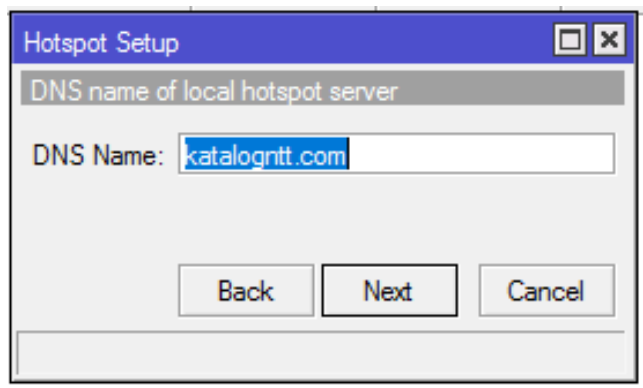

Gambar 12. Seting Nama DNS

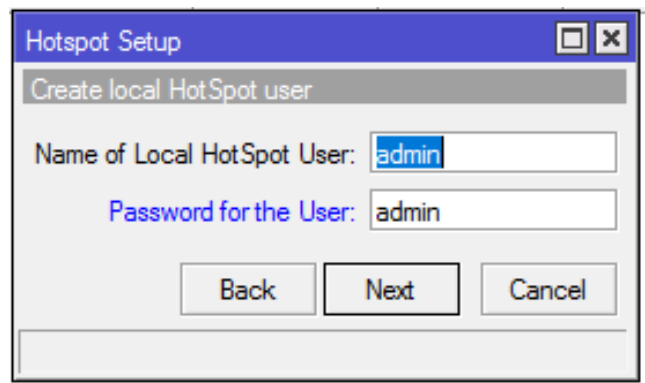

Gambar 13. Seting password untuk admin

Setelah setelah memasukan password untuk admin maka selesailah konfigurasi hotspot.

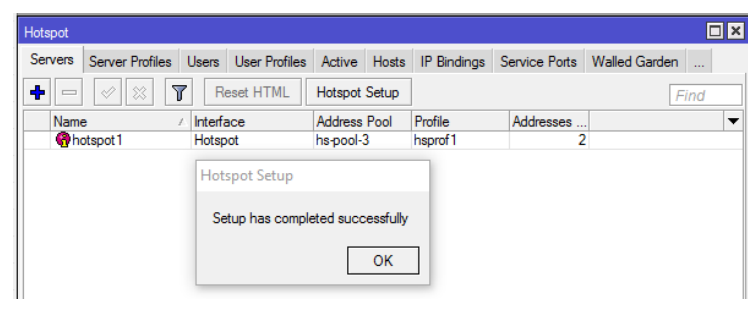

Gambar 14. Hotspot berhasil dibuat

Langkah selanjutnya adalah melakukan testing hotspot dengan membuka browser dan memasukan IP address pada URL Http://201.202.203.1 atau dengan memasukan DNS nya - Http://katalogntt.com jika berhasil maka akan ditampilkan laman login seperti gambar 15 .

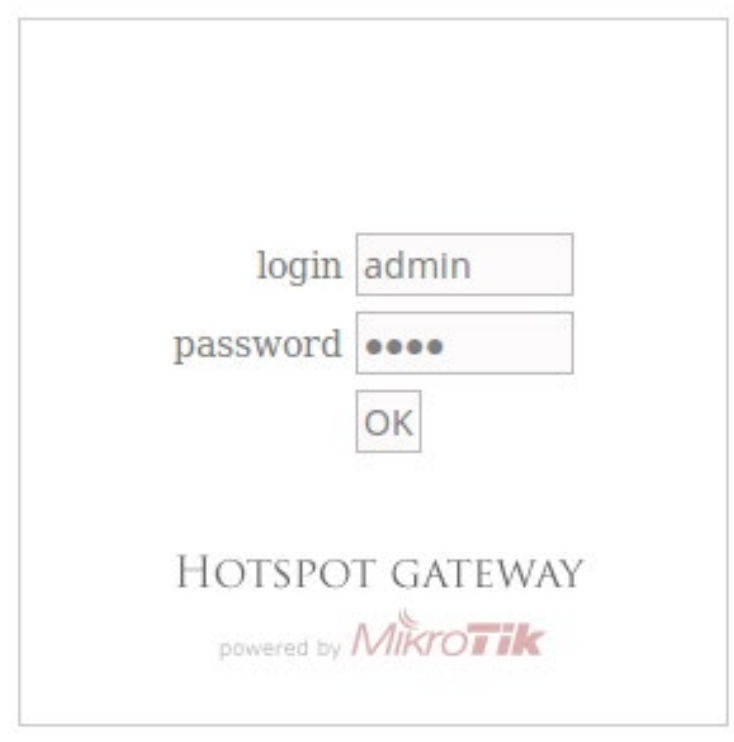

Gambar 15. Login Hotspot 


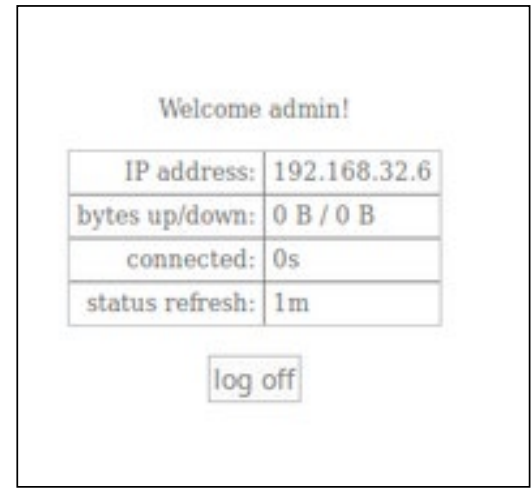

Gambar 16. Logout Hotspot

\subsubsection{Seting Katalog Digital}

Laman Katalog digital sebenarnya adalah modifikasi dari template login dan logout dari hotspot yang sudah berhasil dibuat. Laman Katalog digital didesain dengan memnggunakan template login hotspot dan diberi model responsif sehingga dapat diakses oleh berbagai ukuran layar smartphone, tablet maupun laptop. Folder hasil modifikasi login hotspot menjadi Katalog Digital haruslah dengan nama yang sama, sehingga dapat dikenali oleh router Mikrotik. Kemudian masukkan folder katalog digital tersebut ke memori flash router dengan sistem drag \& drop pada file manager.

Folder Hotspot bawaan router harus dihapus terlebih dahulu dan digantikan dengan folder hotspot yang mengandung laman katalogntt.com. Setelah proses mamasukan folder hotspot selanjutnya router direstart sehingga mengenali login page yang baru.

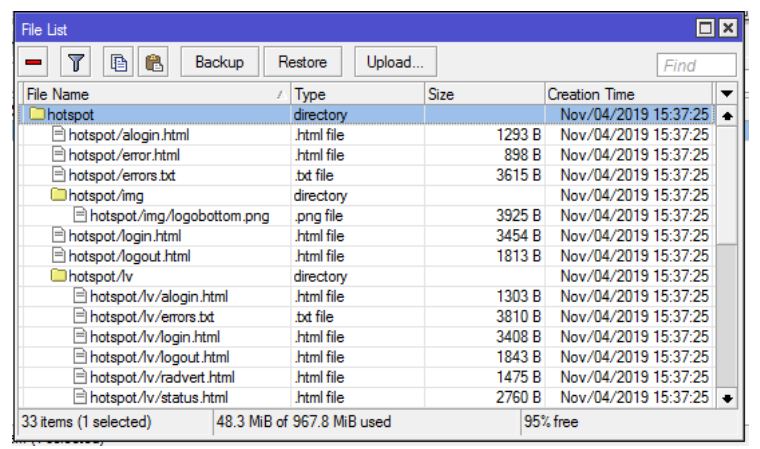

Gambar 17. Proses Memasukkan Login page Hotsot

\subsubsection{Seting Access Point}

Access Point yang digunakan merek TP LINK Model TL-WR 740N. Access Point ini sudah mendukung transfer data sebesar $150 \mathrm{mbps}$ dengan radius jangkaun sejauh seluas $100 \mathrm{~m}^{2}$, namun bila dirasa kurang jauh bisa digantikan dengan akses poin model sektoral yang radiusnya dapat menjangkau lebih dai $1 \mathrm{~km}^{2}$.
Cara seting Setingnya yaitu dengan mengkoneksikan Ethernet TP Link dengan kabel Lan model strike ke komputer, lalu buka browser dan masukan ip address default 192.160.0.1 (tergantung model) sehingga akan muncul halaman login. Untuk login gunakan user name admin dan password admin (default)

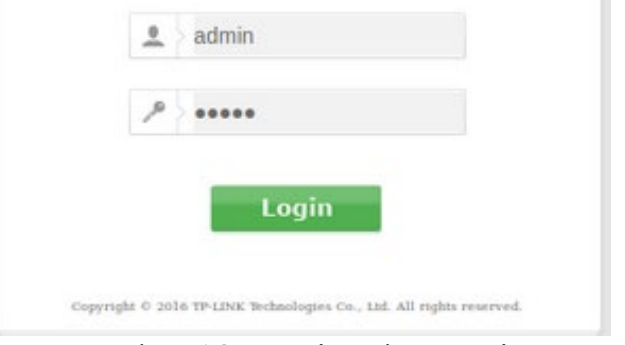

Gambar 18. Login Akses Point

Setelah login, pilih menu Wireless - Wireless Setings. Masukkan Wireless Network Name (SSID) dengan Katalog NTT Hotspot kemudian simpan perubahan tersebut.

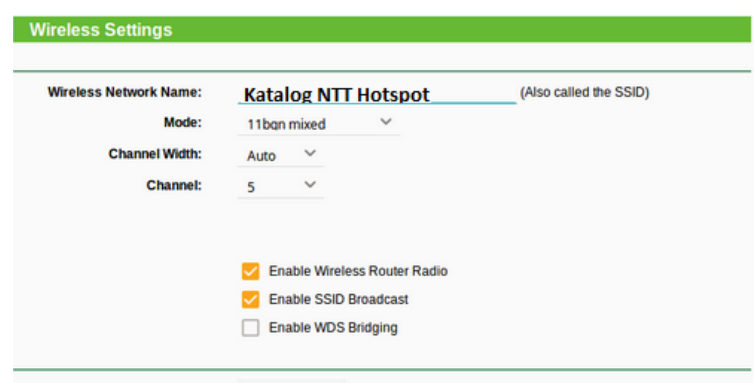

Gambar 19. Seting Nama Hotspot

Buka lagi menu Wireless Security - dan pilih Disable Security dengan tujuan agar pengguna langsung masuk ke login page katalogntt.com. kemudian simpan dan rebot Akses point tersebut.

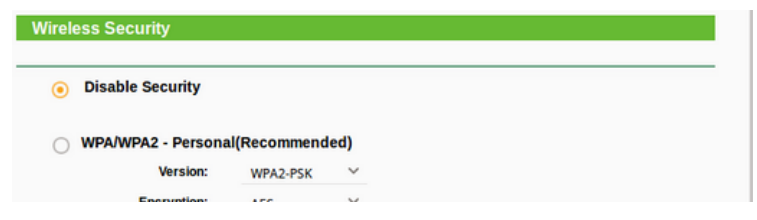

Gambar 20. Disabled Security

\subsection{Konfigurasi Jaringan}

Setelah semua telah dikonfigurasi dengan benar maka tahap selanjutnya melakukan pemasangan jaringan hotspotnya.

a. Sambungkan modem dengan router. Kabel lan harus dimasukkan pada port WAN Router Mikrotik. 
b. Sambungkan kabel lan pada Port 3 (interface hotspot) router Mikrotik ke Access Point TP Link.

c. Pasang Access Point pada ketinggian tertentu sehingga dapat diakses oleh seluruh pengunjung lokasi wisata.

\subsection{Akses katalogntt.com}

Untuk mengakses Katalogntt.com, pengunjung tempat wisata wajib tersambung dengan hotspot Katalog NTT tantpa password. Setelah terkoneksi dengan hotspot, secara otomatis akan diarahkan ke login page katalogntt.com yang tampilannya seperti gambar 21 berikut ini.

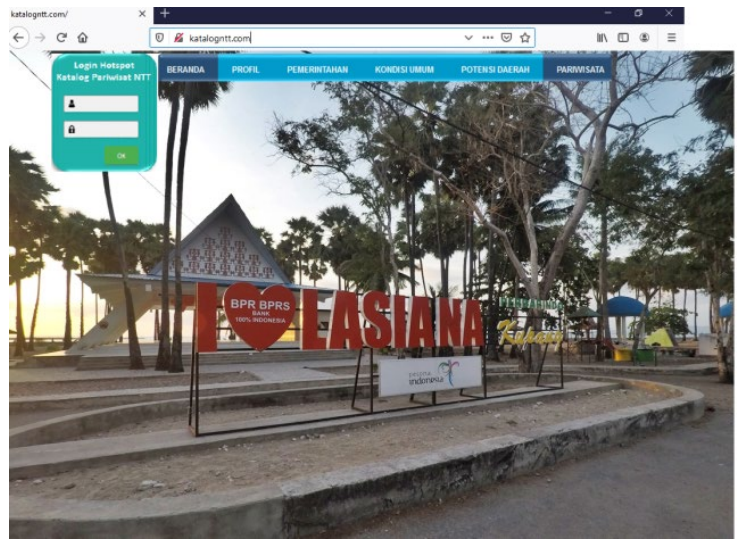

Gambar 20. Laman Web Login Katalog NTT

Pada Tambilan Web terdapat menu Beranda, Profil, Pemerintahan, Kondisi Umum, Potensi Daerah dan Pariwisata yang langsung dapat diakses walaupun tanpa melalui login hotspot. Akses ke menu tersebut sangat cepat karena langsung mengakses laman yang tersimpan pada memory internal router (lokal) sudah termasuk akses proxy.

Bila pengguna menginginkan akses internet, maka harus meminta user name dan password login pada pos pengelola tempat wisata tentunya ada biaya sewa tergantung kebijakan pengelola.

\section{KESIMPULAN}

1. Penerapan router sebagai login hotspot yang dimodifikasi menjadi laman login Katalog NTT menjadikan akses ke katalog NTT sebagai mediia promosi yang bebas tanpa harus menggunakan akses internet.

2. Laman Katalog dapat diunduh dan dirubah kemudian diunggah kembali kedalam memori flsah router, sehingga informasi seputar Pariwisata tersajikan secara aktual.
3. Penggunaan Akses Point menjadikan radius jangkkauan hotspot Katalog NTT menjadi luas sehingga dapat diakses oleh pengunjung lokasi wisata.

4. Biaya pembuatan katalog dapat dihilangkan dan secara langsung sistem router dan access point mendukung go green atau paperless.

5. Penerapan Router dan Access Point mendukung terciptanya konsep digital city dikarenakan tersedianya Wireless Distribution System (WDS) sehingga setiap router dapat saling terhubung yang mana layanan akan dapat diakses pada areal yang sangat luas (Wide Area Network).

\section{DAFTAR PUSTAKA}

[1] https://ilmupengetahuanumum.com/profildaftar-kabupaten-dan-kota-di-provinsinusa-tenggara-timur, diakses tanggal 11 Oktober 2019.

[2] http://nttprov.go.id/2018/index.php/pemeri ntahan/wilayah-administrasi, diakses tanggal 11 Oktober 2019.

[3] https://ntt.bps.go.id/quickMap.html, dakses tanggal 11 Oktober 2019.

[4] Kasim, Bessie and Nyoko/ JOURNAL OF MANAGEMENT (SME's) Vol. 4, No.1, 2017, p71-90.

[5] Undang-Undang Republik Indonesia Nomor 10 Tahun 2009 tentang Kepariwisataan

[6] Mill, R.C.,Tourism System, 4thEd. Kendall/Hunt Publishing Company, New York, 2002.

[7] Suryadana, Mohamad Liga dan Octavia, Vanny., Pengantar Pemasaran Pariwisata, Penerbit Alfabeta, Bandung, 2015.

[8] https://id.wikipedia.org/wiki/Katalog digi tal, diakses tanggal 15 Oktober 2019.

[9] William Starllings, Komunikasi dan Jaringan Nirkabel - Jilid 2, Erlangga, Jakarta, 2019.

[10] https://standards.ieee.org, diakses tanggal 18 Oktober 2019.

[11] Rendra Towidjojo, Mikrotik Kung Fu, Jasakom.com, 2019. 